\title{
Modified technique of transforaminal lumbar interbody fusion for segmental correction of lumbar kyphosis: a safe alternative to osteotomies?
}

\author{
Sebastian Weckbach ${ }^{1 *}$ (D, Heiko Reichel ${ }^{1}$, Michael Kraus ${ }^{1}$, Tugrul Kocak ${ }^{1}$ and Friederike Lattig $^{2}$
}

\begin{abstract}
Background: Sagittal rebalancing of a fixated lumbar hypolordosis (kyphosis) is very important to gain satisfactory results. To correct a misalignment vertebral column resection or pedicle subtraction osteotomies are favored, disregarding the relatively high complication rates. The aim of this study was to evaluate the efficiency and safety of a new modified transforaminal lumbar fusion technique as an alternative.

Methods: We conducted a retrospective review (06/2011-06/2015) of a prospective database at an University hospital. Inclusion criteria were adult patients with a fixated lumbar hypolordosis and the need of monosegmental correction of more than $10^{\circ}$ with an mTLIF. Exclusion criteria consisted of minor aged patients and polysegmental corrections. Study parameters were the perioperative complications and the achieved postsurgical lordosis. The follow up period was 6 months.

Results: A total of 11 patients could be included. The mean segmental lordosis was $-2.3^{\circ} \pm 12.4^{\circ}$ (range $-22^{\circ}$ to $14^{\circ}$ ) preoperative and $15.5^{\circ} \pm 10.5^{\circ}$ (range $0^{\circ}$ to $29^{\circ}$ ) postoperative. The degree of correction was $17^{\circ} \pm 5.7^{\circ}$ in mean per treated segment (range $12^{\circ}$ to $29^{\circ}$ ). No neurologic or vascular complications occurred. No substantial loss of correction or implant failure was noted during the 6-month follow-up.

Conclusion: The modified transforaminal lumbar fusion technique is a safe method to correct a fixated lumbar kyphosis. The potential of segmental correction is comparable to pedicle subtraction osteotomies but sparing potentially healthy segments.
\end{abstract}

Keywords: Sagittal imbalance, Osteotomy, Lumbar spine, Transforaminal lumbar interbody fusion

\section{Background}

Sagittal balance of the spine has been defined as an important factor for patients' satisfaction and prevention of adjacent segment disease in lumbar fusion surgery [1]. Therefore, reconstruction of a physiological lumbar lordosis is a keypoint in spondylodesis independent of the underlying pathology and the surgical procedure used $[2,3]$. Loss of segmental lordosis is mainly due to disc degeneration, discitis or vertebral fracture. The majority of alterated segments remain mobile, which allows the

\footnotetext{
* Correspondence: Sebastian.Weckbach@rku.de

${ }^{1}$ Department of Orthopedics, University of Ulm, Oberer Eselsberg 45, 89081

Ulm, Germany

Full list of author information is available at the end of the article
}

restoration of a lordosis without performing an extended release. Sometimes however the segmental kyphotic deformity is fixed due to large spondylophytes, ossification of the anulus and anterior longitudinal ligament. To restore a physiological lordosis, a circumferential release of the affected segment is necessary which is performed via an anterior-posterior approach. Alternatively a wedge osteotomy like pedicle subtraction osteotomy (PSO) or vertebral column resection (VCR) could be performed [4]. Using these techniques a correction of the sagittal profile and a restoration of lumbar lordosis up to 35 degrees can bei achieved. However going along with a high complication rate especially neural injuries and high intraoperative blood loss [5]. In addition, further 
Table 1 Patients demographics: Patients age, treated segments, diagnosis and past surgical history

\begin{tabular}{llllll}
\hline Pat & Age & Gender & Level mTLIF & Preop. diagnosis & Previous surgery \\
\hline 1 & 67 & $\mathrm{~m}$ & $\mathrm{~L} 4 / 5$ & Osteochondrosis & none \\
2 & 46 & $\mathrm{f}$ & $\mathrm{L} 4 / 5$ & Osteochondrosis & Decompression same level \\
3 & 78 & $\mathrm{f}$ & $\mathrm{L} 3 / 4$ & Osteochondrosis & Laminectomy L4 \\
4 & 56 & $\mathrm{f}$ & $\mathrm{L} 3 / 4$ & Deg. kyphoscoliosis & none \\
5 & 45 & $\mathrm{f}$ & $\mathrm{L} 4 / 5$ & Osteochondrosis & none \\
6 & 69 & $\mathrm{~m}$ & $\mathrm{~L} 2 / 3$ & latrogenic kyphosis with fracture & Verteboplasty, Laminectomy \\
7 & 48 & $\mathrm{~m}$ & $\mathrm{~L} 3 / 4$ & Lytic spondylolisthesis & none \\
8 & 42 & $\mathrm{f}$ & $\mathrm{L} 3 / 4$ & Osteochondrosis & Distraction fusion L4-S1 \\
9 & 73 & $\mathrm{~m}$ & $\mathrm{~L} 4 / 5$ & Deg. kyphoscoliosis & none \\
10 & 65 & $\mathrm{~m}$ & $\mathrm{~L} 2 / 3$ & Osteochondrosis & Fusion L3-S1, Neurostimulator \\
11 & 42 & $\mathrm{f}$ & $\mathrm{L} 1 / 2$ & Fracture L1 & none
\end{tabular}

potentially healthy segments have to be included in those fusion procedures for stability reasons. In general, anterior-posterior approaches and 3-column osteotomies are associated with high perioperative complication rates of more than $30 \%$ [6].

Using the widely established technique of the unilateral transforaminal lumbar interbody fusion (TLIF) for the circumferential release with anterior cage support could help to avoid these typical complications and spare unaffected segments. The purpose of this study was to evaluate the reconstructive potential of lumbar lordosis in fixed kyphotic segments via a modified unilateral transforaminal approach mTLIF.

\section{Methods}

During a four year study period $(06 / 2011-06 / 2015)$ at a German University hospital consecutively all adult patients fulfilling the inclusion criteria were included in the study. A retrospective review of a prospective database was carried out. Inclusion criteria were adult patients with a fixated monosegmental lumbar hypolordosis undergoing surgical correction of the sagittal profile within the index segment aiming for a correction of more than $10^{\circ} \mathrm{Cobb}$ angle. Radiological documentation with standard upright $\mathrm{X}$-rays of the lumbar spine was taken preoperatively as well as 1 and 6 weeks and 6 months postoperatively. Children and patients with multilevel pathology were excluded.

Study parameters were the angles of lordosis of the treated segment measured by the Cobb's method on a lateral standing $\mathrm{x}$-ray. Furthermore, periinterventional complications and blood loss were evaluated.

Surgical technique: After exposure of the affected segment from posterior and insertion of the pedicle screws a typical transforaminal approach is performed from one side. The ipsilateral facet joint is resected, whereas on the opposite the joint is only reduced with removing the capsule, remaining cartilage and osteophytes. If necessary the spinal canal could be decompressed in cross-over technique. The remaining disc material is removed as much as

Table 2 Surgical implants: Cage type, absolute and mean measures \pm SD and correction for lumbar lordosis (LL) and lordosis of the mTLIF segment (SL)

\begin{tabular}{|c|c|c|c|c|c|}
\hline Pat & Cage & SL preop & SL 1 week postop & SL 6 mo postop & Correction mTLIF segment \\
\hline 1 & Banana $6^{\circ}$ & $-6^{\circ}$ & $6^{\circ}$ & $6^{\circ}$ & $12^{\circ}$ \\
\hline 2 & Mesh $0^{\circ}$ & $14^{\circ}$ & $26^{\circ}$ & $26^{\circ}$ & $12^{\circ}$ \\
\hline 3 & Banana $10^{\circ}$ & $3^{\circ}$ & $17^{\circ}$ & $16^{\circ}$ & $13^{\circ}$ \\
\hline 4 & Mesh $0^{\circ}$ & $0^{\circ}$ & $13^{\circ}$ & $12^{\circ}$ & $12^{\circ}$ \\
\hline 5 & Banana $10^{\circ}$ & $12^{\circ}$ & $26^{\circ}$ & $26^{\circ}$ & $14^{\circ}$ \\
\hline 6 & Mesh $0^{\circ}$ & $-18^{\circ}$ & $0^{\circ}$ & $0^{\circ}$ & $18^{\circ}$ \\
\hline 7 & Banana $6^{\circ}$ & $-5^{\circ}$ & $12^{\circ}$ & $11^{\circ}$ & $16^{\circ}$ \\
\hline 8 & Mesh $28^{\circ}$ & $-2^{\circ}$ & $27^{\circ}$ & $27^{\circ}$ & $29^{\circ}$ \\
\hline 9 & Banana $10^{\circ}$ & $13^{\circ}$ & $29^{\circ}$ & $28^{\circ}$ & $15^{\circ}$ \\
\hline 10 & Banana $10^{\circ}$ & $-14^{\circ}$ & $13^{\circ}$ & $10^{\circ}$ & $24^{\circ}$ \\
\hline \multirow[t]{2}{*}{11} & Banana $6^{\circ}$ & $-22^{\circ}$ & $1^{\circ}$ & $0^{\circ}$ & $22^{\circ}$ \\
\hline & & $-2.3^{\circ} \pm 12.4^{\circ}$ & $15.5^{\circ} \pm 10.5^{\circ}$ & $14.7^{\circ} \pm 10.7^{\circ}$ & $17^{\circ} \pm 5.7^{\circ}$ \\
\hline
\end{tabular}


possible. Small curved curretts and rongeurs are helpful for this step. If the disc space is very small a chisel could be used as well. The release of the lateral and anterior structures starts from the already performed incision of the ipsilateral annulus. The descending nerve root is protected and the lateral annulus is dissected in anterograde direction with a sharp instrument, e.g. an $8 \mathrm{~mm}$ chisel. As soon as some mobility of the segment is achieved, a posterior distraction of the segment via the pedicle screws or the posterior spinous process is performed. Then the anterior part of the annulus with the anterior longitudinal ligament is dissected either with a punch or a chisel cutting backwards starting as far as possible on the contralateral side. Afterwards a plain spreader is inserted between the vertebral bodies. With a dosed force the segment is spread until the remaining posterolateral fibres of the contralateral annulus are torn and the segment is completely mobile.

The study protocol fulfilled the requirements by the University Ethics Committee Ulm, Germany and was approved. The statistics were descriptive and results presented in mean values.

\section{Results}

Regarding the inclusion and exclusion criteria overall 11 patients were eligible for a monosegmental correction using the mTLIF. Out of these patients, seven were female and four male with a mean age of 57 years
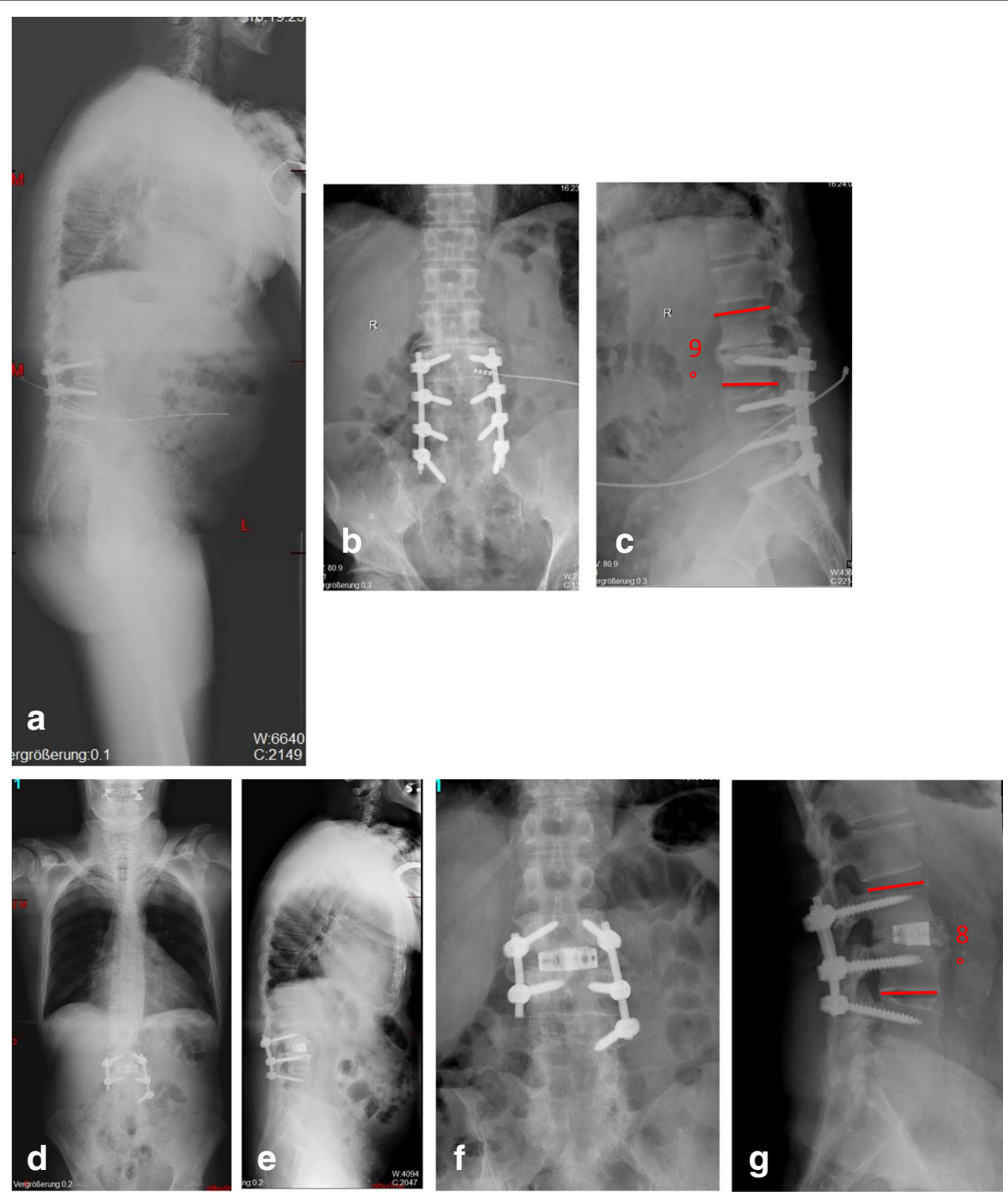

Fig. 1 65- year old male with fixed adjacent segment disease L2/3 post posterior instrumentation and fusion L3-S1 including the implantation of an neurological stimulator in an outside hopsital. Figure $\mathbf{a}$ shows the sagittal whole-spine $\mathbf{x}$-ray, Figure $\mathbf{b}$ the standing ap $\mathbf{x}$-ray of the lumbar spine, Figure $\mathbf{c}$ the lateral $\mathbf{x}$-ray including the measurements of the deformity. Figures $\mathbf{d}$ and $\mathbf{e}$ display the postop standing whole-spine $\mathbf{x}$-rays, Figures $\mathbf{f}$ and $\mathbf{g}$ the lumbar $\mathbf{x}$-rays including the measurements 
(range 42 to 78 y). Five patients had previous lumbar spine surgery. Indication for surgery was mainly degenerative disc disease. The level of the surgical intervention was in one case L1/2, in two cases L2/3 and in four cases L3/4 and L4/5. The patient specific characteristics were shown in Table 1.

The mean segmental lordosis was $-2.3^{\circ} \pm 12.4^{\circ}$ (Range $-22^{\circ}$ to $13^{\circ}$ Cobb-angle) preoperatively. One week after mTLIF the mean segmental lordosis was measured with $15.5^{\circ} \pm 10.5^{\circ}$ (Range $\left.0^{\circ}-28^{\circ}\right)$. These results could be confirmed at the 6- month follow- up with a mean segmental lordosis of $14.7^{\circ} \pm 10.7\left(0^{\circ}\right.$ to $\left.28^{\circ}\right)$. The correction potential of the mTLIF with the $270^{\circ}$ release was in mean $17^{\circ} \pm 5.7^{\circ}$ (Range $12^{\circ}$ to $29^{\circ}$ ). Loss of segmental lordosis between one week and 6 months postoperatively was $0.7^{\circ}$ (Range $0^{\circ}$ to $3^{\circ}$ ). The results are shown in Table 2 in detail. Exemplary for the surgical intervention, clinical cases are shown in Figs. 1 and 2.
Regarding complications, neither major complications such as major vessel injury or neurologic deficit nor minor complications like wound infections occured. The 6-month follow- up didn't reveal any signs of implant failure or screw loosening.

\section{Discussion}

The importance of sagittal balancing of the spine is getting more and more into focus. Restoration of the sagittal balance reduces pain and improves gait efficiency [7]. Fixed sagittal deformities are corrected generally using different osteotomies like PSO or VCR. We hypothetized that fixed spinal sagittal deformities could also be adressed using the above described modification of the commonly known TLIF procedure. Using this technique, almost $270^{\circ}$ release of the disc anulus can be achieved even in fixed segments. Therefore, the mTLIF is a safe alternative procedure for rebalancing the lumbar spine
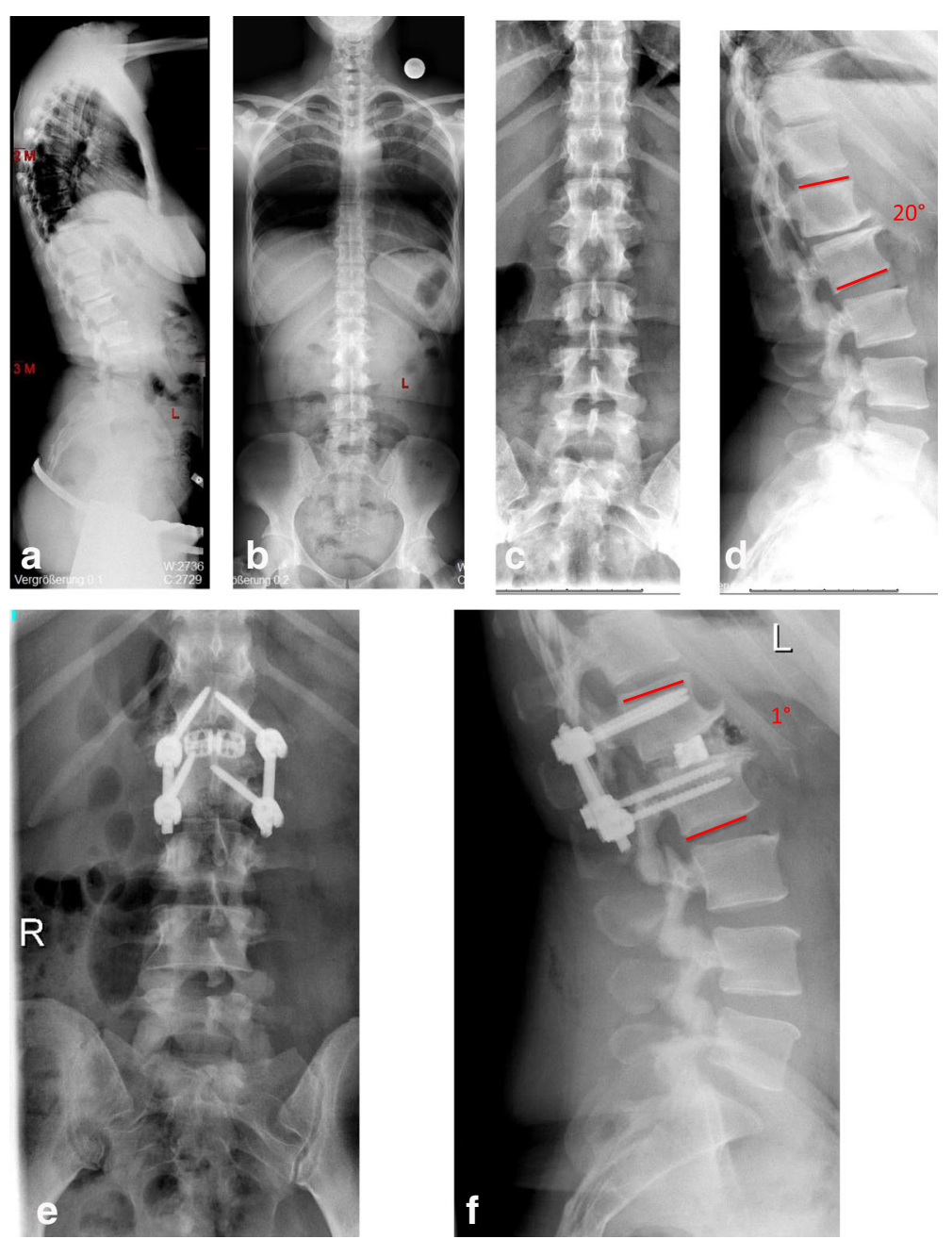

Fig. 2 42-year old female with status post L1 fracture and segmental kyphosis L1/2. Figures $\mathbf{a} / \mathbf{b}$ display the whole spine $x$-rays, Figures $\mathbf{c} / \mathbf{d}$ the lumbar $\mathrm{x}$-rays in both planes including the measurements of the deformity. Figures $\mathbf{e} / \mathbf{f}$ show the postop standing $\mathrm{x}$-rays of the lumbar spine including the measurements in both planes 
in selected indications. Our data revealed a correction potential of up to $25^{\circ}$ per segment.

Correction of deformities using osteotomies requires additional fixation of potentially healthy segments. For PSO Berjano et al. [4] recommended to extend the fixation two levels above and two levels below the index segment. For PSO, a correction of $17.9^{\circ}+/-4.3^{\circ}$ is described [8]. Furthermore, the bilateral approach and the closing wedge resection in PSO may be as well causative for the high risk of neurologic complications. Complications in PSO are described in literature ranging from 4 to $15 \%$ [9-11].

In patients with remaining mobility in unaffected lumbar segments, a fixation of these segments should be avoided whenever possible. Any type of reconstructing lumbar lordosis by spinal osteotomy involving the anterior column cannot be fused monosegmentally. Using the mTLIF technique a single level spondylodesis including the segmental restoration of lordosis can be achieved. In our series the patients were treated solely monosegmentally without implant failure. In one case, a slightly loss of correction of $3^{\circ}$ after 6 months was observed. Nevertheless, a higher loss of correction and subsidence of the cages during the follow-up period of 6 months was not documented. This technique could even be simplified using an expandable model of TLIF - cage with a variety of lordotic angles up to $25^{\circ}$. If the difference between the segmental lordosis and the cage lordosis increases, the contact area of the cage and the vertebral endplates is diminished with increasing risk for subsidence of the cage. Different studies support that cages with larger bearing surface show less subsidence [12-14].

The main working zone of the mTLIF technique is the disc space. Larger spondylophytes and a partially ossificated disc could be addressed with the technique as shown. To benefit from the advantages, particularly the estimated minor blood loss and the possibly lower risk for neurologic complications, the authors do not recommend the technique in segments with totally ossification of the disc e.g. as in patients with ankylosing spondylitis. Furthermore, in cases requiring a segmental lordosis of more than $25^{\circ}$, the mTLIF technique is at its limit and the classical osteotomies such as PSO should be used. Whether a polysegmental mTLIF could be an alternative to vertebral osteotomies in those cases is currently under evaluation.

This study is, to the best of the authors knowledge, the first description of the surgical technique and evaluation of patients treated with single level mTLIF. Certainly, the study cohort was small, the investigation was not designed as a matched control study and the patients were not randomized. The follow- up period of 6 months was short but in context with the literature, the occurrence of radiolucent zones around pedicle screws as a sign of a developing pseudarthrosis is at its peak about 6 months postoperatively $[15,16]$. Hence, the period seems to be sufficient to evaluate, if the mTLIF construct provides enough stability and is comparable to instrumentations in bony osteotomies.

\section{Conclusion}

The mTLIF technique is a safe and effective method correcting segmental lumbar hypolordosis up to $25^{\circ}$. The less extensive approach compared to bony osteotomies can help to reduce blood loss and spare potentially healthy segments. Therefore, the mTLIF should be considered as an alternative to a PSO in selected cases.

\section{Acknowledgements}

SW, HR and FL had the idea for the study and designed it. TK and MK assisted in data collection and drafting the manuscript. All authors contributed substantially to this study.

\section{Funding}

There was no funding for this study for all authors.

\section{Availability of data and materials \\ Not applicable.}

\section{Declarations}

The publication costs for this article were covered in full by a grant from the Colorado Physician Insurance Company (www.copic.com) to Philip F. Stahel, MD. COPIC had no influence on authorship or scientific content of this article.

\section{Authors' contribution}

SW, HR and FL conceived the idea for the study, study design and data collection. TK and MK contributed to the study in assisting for data collection, case presentations and drafting the manuscript. All authors read and approved the final manuscript.

\section{Ethics approval and consent to participate}

The study protocol fulfilled the requirements by the University Ethics Committee Ulm, Germany and was approved.

\section{Consent for publication}

All authors gave consent for publication.

\section{Competing interests}

All authors declare that they have no competing interests.

\section{Publisher's Note}

Springer Nature remains neutral with regard to jurisdictional claims in published maps and institutional affiliations.

\section{Author details}

${ }^{1}$ Department of Orthopedics, University of Ulm, Oberer Eselsberg 45, 89081 Ulm, Germany. ${ }^{2}$ Spine Center, Berit Paracelsus Clinic, Voegelinsegg 5, 9042 Speicher, Switzerland.

Received: 22 May 2017 Accepted: 28 June 2017

Published online: 05 July 2017

References

1. Matsumoto T, Okuda S, Maeno T, Yamashita T, Yamasaki R, Sugiura T, Iwasaki M. Spinopelvic sagittal imbalance as a risk factor for adjacentsegment disease after single-segment posterior lumbar interbody fusion. J Neurosurg Spine. 2017;26(4):435-40.

2. Bridwell KH, Baldus C, Berven S, Edwards C 2nd, Glassman S, Hamill C, Horton W, Lenke LG, Ondra S, Schwab F, et al. Changes in radiographic and clinical outcomes with primary treatment adult spinal deformity surgeries 
from two years to three- to five-years follow-up. Spine (Phila Pa 1976). 2010; 35(20):1849-54

3. Schwab FJ, Lafage V, Farcy JP, Bridwell KH, Glassman S, Shainline MR. Predicting outcome and complications in the surgical treatment of adult scoliosis. Spine (Phila Pa 1976). 2008;33(20):2243-7.

4. Berjano P, Aebi M. Pedicle subtraction osteotomies (PSO) in the lumbar spine for sagittal deformities. Eur Spine J. 2015;24(Suppl 1):S49-57.

5. Wang MY, Berven SH: Lumbar pedicle subtraction osteotomy. Neurosurgery 2007, 60(2 Suppl 1):ONS140-146; discussion ONS146.

6. Auerbach JD, Lenke LG, Bridwell KH, Sehn JK, Milby AH, Bumpass D, Crawford $\mathrm{CH}$ 3rd, O'Shaughnessy BA, Buchowski JM, Chang MS, et al. Major complications and comparison between 3-column osteotomy techniques in 105 consecutive spinal deformity procedures. Spine (Phila Pa 1976). 2012;37(14):1198-210.

7. Lagrone MO, Bradford DS, Moe JH, Lonstein JE, Winter RB, Ogilvie JW. Treatment of symptomatic flatback after spinal fusion. J Bone Joint Surg Am. 1988;70(4):569-80

8. Chen F, Kang Y, Zhou B, Dai Z. Correction of posttraumatic thoracolumbar kyphosis with modified pedicle subtraction osteotomy. Zhong Nan Da Xue Xue Bao Yi Xue Ban. 2016;41(11):1208-14.

9. Bridwell KH, Lewis SJ, Edwards C, Lenke LG, Iffrig TM, Berra A, Baldus C, Blanke K. Complications and outcomes of pedicle subtraction osteotomies for fixed sagittal imbalance. Spine (Phila Pa 1976). 2003;28(18):2093-101.

10. Buchowski JM, Bridwell KH, Lenke LG, Kuhns CA, Lehman RA Jr, Kim YJ, Stewart D, Baldus C. Neurologic complications of lumbar pedicle subtraction osteotomy: a 10-year assessment. Spine (Phila Pa 1976). 2007;32(20):2245-52.

11. Yang BP, Ondra SL, Chen LA, Jung HS, Koski TR, Salehi SA. Clinical and radiographic outcomes of thoracic and lumbar pedicle subtraction osteotomy for fixed sagittal imbalance. J Neurosurg Spine. 2006;5(1):9-17.

12. Faizan A, Kiapour A, Kiapour AM, Goel VK. Biomechanical analysis of various footprints of transforaminal lumbar interbody fusion devices. I Spinal Disord Tech. 2014;27(4):E118-27.

13. Tan JS, Bailey CS, Dvorak MF, Fisher CG, Oxland TR. Interbody device shape and size are important to strengthen the vertebra-implant interface. Spine (Phila Pa 1976). 2005;30(6):638-44

14. Tokuhashi Y, Ajiro Y, Umezawa N. Subsidence of metal interbody cage after posterior lumbar interbody fusion with pedicle screw fixation. Orthopedics. 2009;32(4).

15. Tokuhashi Y, Matsuzaki H, Oda H, Uei H. Clinical course and significance of the clear zone around the pedicle screws in the lumbar degenerative disease. Spine (Phila Pa 1976). 2008;33(8):903-8.

16. Wu JC, Huang WC, Tsai HW, Ko CC, Wu CL, Tu TH, Cheng H. Pedicle screw loosening in dynamic stabilization: incidence, risk, and outcome in 126 patients. Neurosurg Focus. 2011;31(4):E9.

\section{Submit your next manuscript to BioMed Central and we will help you at every step:}

- We accept pre-submission inquiries

- Our selector tool helps you to find the most relevant journal

- We provide round the clock customer support

- Convenient online submission

- Thorough peer review

- Inclusion in PubMed and all major indexing services

- Maximum visibility for your research

Submit your manuscript at wuw biomedcentral.com/submit

) Biomed Central 